\title{
Validity of self-reported weight, height, and body mass index among university students in Thailand: Implications for population studies of obesity in developing countries Lynette LY Lim*1, Sam-ang Seubsman² and Adrian Sleigh ${ }^{1}$
}

\author{
Address: ${ }^{1}$ National Centre for Epidemiology and Population Health, Australian National University, Canberra, Australia and ${ }^{2}$ School of Human \\ Ecology, Sukhothai Thammathirat Open University, Pakkret, Thailand \\ Email: Lynette LY Lim* - lynette.lim@anu.edu.au; Sam-ang Seubsman - sam-ang@mail.com; Adrian Sleigh - adrian.sleigh@anu.edu.au \\ * Corresponding author
}

Published: 25 September 2009

Population Health Metrics 2009, 7:15 doi:10.1186/1478-7954-7-15
Received: 6 May 2009

Accepted: 25 September 2009

This article is available from: http://www.pophealthmetrics.com/content/7/1/15

(c) 2009 Lim et al; licensee BioMed Central Ltd.

This is an Open Access article distributed under the terms of the Creative Commons Attribution License (http://creativecommons.org/licenses/by/2.0), which permits unrestricted use, distribution, and reproduction in any medium, provided the original work is properly cited.

\begin{abstract}
Background: Large-scale epidemiological studies commonly use self-reported weights and heights to determine weight status. Validity of such self-reported data has been assessed primarily in Western populations in developed countries, although its use is widespread in developing countries. We examine the validity of obesity based on self-reported data in an Asian developing country, and derive improved obesity prevalence estimates using the "reduced BMI threshold" method.

Methods: Self-reported and measured heights and weights were obtained from 741 students attending an open university in Thailand (mean age 34 years). Receiver operator characteristic techniques were applied to derive "reduced BMI thresholds."

Results: Height was over-reported by a mean of $1.54 \mathrm{~cm}$ (SD 2.23) in men and $1.33 \mathrm{~cm}(1.84)$ in women. Weight was under-reported by $0.93 \mathrm{~kg}(3.47)$ in men and $0.62 \mathrm{~kg}(2.14)$ in women. Sensitivity and specificity for determining obesity (Thai BMl threshold $25 \mathrm{~kg} / \mathrm{m}^{2}$ ) using self-reported data were $74.2 \%$ and $97.3 \%$, respectively, for men and $71.9 \%$ and $100 \%$ for women. For men, reducing the BMI threshold to $24.5 \mathrm{~kg} / \mathrm{m}^{2}$ increased the estimated obesity prevalence based on selfreports from $29.1 \%$ to $33.8 \%$ (true prevalence was $36.9 \%$ ). For women, using a BMI threshold of $24.4 \mathrm{~kg} / \mathrm{m}^{2}$, the improvement was from $12.0 \%$ to $15.9 \%$ (true prevalence $16.7 \%$ ).

Conclusion: Young educated Thais under-report weight and over-report height in ways similar to their counterparts in developed countries. Simple adjustments to BMI thresholds will overcome these reporting biases for estimation of obesity prevalence. Our study suggests that self-reported weights and heights can provide economical and valid measures of weight status in high schooleducated populations in developing countries.
\end{abstract}

\section{Introduction}

Body mass index (BMI), calculated as weight in kilograms divided by the square of height in meters, is widely used to classify body size as underweight, normal, overweight, or obese. In Western populations, an adult with BMI of 30 $\mathrm{kg} / \mathrm{m}^{2}$ or over is considered obese [1]. Epidemiological studies involving large numbers of people frequently replace actual weight and height measurements with self- 
reported data. Many studies have shown that self-reports correlate highly with measured data [2-4]. But studies also consistently noted systematic bias in self-reported data, with height generally overestimated and weight generally underestimated [5]. Thus, self-reported BMI is most often lower than measured BMI $[5,6]$; as a result, some obese individuals are misclassified as nonobese, leading to underestimation of obesity prevalence.

Dauphinot (2008) proposed a simple and intuitive method to obtain better estimates of obesity prevalence from self-reports [7]. Instead of defining obesity at the 30 $\mathrm{kg} / \mathrm{m}^{2}$ threshold, the method proposes a "reduced BMI threshold" derived using receiver operator characteristic (ROC) techniques. In their population, by reducing the BMI threshold to $29.2 \mathrm{~kg} / \mathrm{m}^{2}$, they obtained obesity prevalence estimates from self-reports that were not significantly different from the true values. For application in populations with different characteristics, it was recommended that reduced BMI thresholds be computed from ancillary data collected on a limited representative sample [7].

Research on the validity of self-reported weight, height, and BMI have been performed primarily on Western populations in developed countries. A recent systematic review [5] of the validity of self-reported BMI comprising 64 studies found only two conducted on Asian populations, both Japanese [4,8]. The accuracy of self-reported BMI was found to vary by age, sex, socioeconomic status, actual weight status, ethnicity, and perceived body image [4,9-12]. The accuracy of self-reported weight and height in Asian people may differ from Western populations because of differences in body size and cultural norms. For example, an international comparison of 22 countries found that the perceptions of overweight and attempts to lose weight were highest in Asian nations [13]. Findings on the validity of self-reported anthropometric measurements in Western populations may not generalize to Asian populations.

The present work was motivated by the need to assess weight status in a large cohort study of health risk transition in Thailand, the Thai Cohort Study (TCS) [14]. More than 80,000 students from across Thailand enrolled at the Sukhothai Thammathirat Open University (STOU) participated in the baseline TCS survey, reporting their weight and height as part of a 20-page mailed-out questionnaire. Here, we investigate the validity of self-reported cohort weights and heights using ancillary data from an independent sample of 741 STOU men and women. We assess the validity of body size estimates based on these selfreported weights and heights in a Thai population, and we evaluate obesity prevalence estimates using the "reduced BMI threshold" method.

\section{Methods \\ Study population}

STOU students attend an on-campus course in their final semester devoted to professional and ethical issues. Each batch is about 350 students from all over the country, usually well-balanced between male and female. These students were recruited for this study on three occasions between December 2005 and May 2007. Participation was voluntary. Students were encouraged to participate as a "contribution to society" and were asked to self-report their weight and height by filling in a one-page form. They were not informed at the time about actual measurements. They were given a "BMI kit" that explained the utility and computation of BMI when they returned the selfreport form and were invited at that time to volunteer for measurements by our research assistant.

\section{Data collection}

The self-report form asked for height (without shoes) in centimeters and weight in kilograms to the nearest whole centimeter and kilogram, respectively. The self-report and measured data were obtained on the same day. All of the weight and height measurements were performed by one research assistant on each occasion. Weight was measured using an electronic Seca scale, which was calibrated and checked for accuracy by the company representing the manufacturer the day before it was used. Height was measured to the nearest half-centimeter using a stadiometer. The students were instructed to stand with their feet together and to look straight ahead.

\section{Height and weight variables}

Measured BMI was defined as the BMI calculated from measured weight and height, and self-reported BMI as the BMI calculated from self-reported weight and height. Discrepancies were assessed by the differences between selfreported and measured weight, height, and BMI. Weight discrepancies of more than $5 \mathrm{~kg}$, height discrepancies of more than $10 \mathrm{~cm}$, and BMI below $10 \mathrm{~kg} / \mathrm{m}^{2}$ or above 45 $\mathrm{kg} / \mathrm{m}^{2}$ were checked for data entry errors.

Obesity was defined as $\mathrm{BMI} \geq 25 \mathrm{~kg} / \mathrm{m}^{2}$ and overweight as $\mathrm{BMI} \geq 23 \mathrm{~kg} / \mathrm{m}^{2}$, in accordance with WHO criteria for Asian populations [15]. The sensitivities and specificities of the obese and overweight categories based on self-reported BMI were calculated using measured BMI as the standard of comparison: sensitivity is the probability of true positives and specificity the probability of true negatives. Positive predictive values (PPV) and negative predictive values (NPV) were also computed. PPV (for obesity) reflects the probability that a person classified as obese from self-reported information is truly obese, and is the most important indicator of the utility of self-reported weights and heights as a tool for determining obesity. NPV (for obesity) reflects the probability that a person not 
classified as obese is truly not obese. PPV and NPV depend on sensitivity and specificity as well as on prevalence.

\section{Statistical methods}

As the validity of self-reported weight and height differ between men and women, separate analyses were done for each sex. Statistical analyses were performed using Stata Version 9.0. Statistical methods included the use of descriptive parameters (mean, standard deviation), Spearman's rank correlation coefficient, chi-squared and paired t-test. Confidence intervals were calculated using the normal approximation for standard errors of proportions. Binary variables measuring rounding effect were also computed for self-reported weight and height - "end-digit preference" for values ending in zero or five were compared to the other values ending in 1 to 4 or 6 to $9[2,15]$. The proportion with end-digit preference was compared to the expected proportion of $20 \%$.

\section{Reduced BMI threshold}

The Dauphinot method [7] obtains improved estimates of prevalence from self-reported weights and heights by lowering the threshold used to define obesity (or overweight/ obese). The reduced BMI threshold defining obesity (or overweight/obese) is determined from receiver operator characteristic (ROC) curve analysis by selecting the (highest) BMI value, which maximizes the percentage of people correctly classified.

\section{Results}

The subjects were aged 21 to 62 years. The mean ages for men and women were 34.7 years (SD 8.4) and 34.1 years (SD 7.9), respectively.

There were strong correlations between measured and self-reported values in weight, height, and BMI for both men and women (Spearman's correlation for men and women respectively: 0.95 and 0.97 for weight, 0.94 and 0.94 for height, 0.91 and 0.95 for BMI) (Table 1).

Both men and women statistically significantly underreported their weights and over-reported their heights (Table 1). On average, men under-reported weight by $0.93 \mathrm{~kg}$ and over-reported height by $1.54 \mathrm{~cm}$. Women under-reported weight by $0.62 \mathrm{~kg}$ and over-reported height by $1.33 \mathrm{~cm}$. Consequently, BMI calculated from self-reported data significantly under-reported measured BMI by $0.77 \mathrm{~kg} / \mathrm{m}^{2}$ and $0.62 \mathrm{~kg} / \mathrm{m}^{2}$ for men and women, respectively.

\section{Reporting discrepancies by measured BMI category}

Table 2 examines the effect of actual weight status on discrepancies in weight and height reporting. Increasing weight status was strongly associated with more pronounced under-reporting of weight as well as over-reporting of height for both sexes. On average, weight was under-reported by $0.3 \mathrm{~kg}, 1.2 \mathrm{~kg}$, and $1.8 \mathrm{~kg}$, respectively, in normal weight, overweight, and obese individuals. Underweight individuals tended to over-report weight. Height was over-reported in both sexes. In normal weight individuals, the over-reporting of height, by $1.18 \mathrm{~cm}$ in men and $1.13 \mathrm{~cm}$ in women, was highly statistically significant. In overweight men and women, height was significantly over-reported by $1.69 \mathrm{~cm}$ and $1.36 \mathrm{~cm}$, respectively, and in obese men and women, by $1.92 \mathrm{~cm}$ and $1.83 \mathrm{~cm}$, respectively. Underweight females overreported height by $1.7 \mathrm{~cm}$, but underweight males underreported height by $1.4 \mathrm{~cm}$.

Overall, $35 \%$ of men and $28 \%$ of women showed "enddigit preference" (the tendency to round digits to zero or five) in reporting weight, and $37 \%$ and $34 \%$, respectively, in reporting height. Except for underweight men, for which there were too few subjects, and underweight and

Table I: Self-reported and measured anthropometric measurements, their discrepancies and correlations separately for men $(\mathrm{n}=$ 358) and women $(n=383)$

\begin{tabular}{|c|c|c|c|c|}
\hline & $\begin{array}{c}\text { Self-reported } \\
\text { Mean (SD) }\end{array}$ & $\begin{array}{l}\text { Measured } \\
\text { Mean (SD) }\end{array}$ & $\begin{array}{c}\text { Discrepancy } \\
\text { (Self-reported - Measured) } \\
\text { Mean }(95 \% \mathrm{Cl})\end{array}$ & $\begin{array}{c}\text { Correlation } \\
\rho \text { (p-value) }\end{array}$ \\
\hline \multicolumn{5}{|l|}{ Weight, kg } \\
\hline Men & $67.6 \quad$ (II.7) & $68.5 \quad(12.1)$ & $-0.93(-1.29,-0.57)^{* * *}$ & $0.95 \quad(<0.000 I)$ \\
\hline Women & $53.8 \quad(9.1)$ & $54.5 \quad(9.8)$ & $-0.62(-0.83,-0.40)^{* * *}$ & $0.97 \quad(<0.0001)$ \\
\hline \multicolumn{5}{|l|}{ Height, $\mathrm{cm}$} \\
\hline Men & 168.6 & $167.1 \quad(6.0)$ & $1.54 \quad(1.31,1.77)^{* * * *}$ & $0.94 \quad(<0.0001)$ \\
\hline Women & 157.9 & $156.6 \quad(5.2)$ & $1.33(1.15,1.51)^{* * * *}$ & $0.94 \quad(<0.0001)$ \\
\hline \multicolumn{5}{|l|}{ BMI, kg/m² } \\
\hline Men & $23.7 \quad(3.6)$ & $24.5 \quad(3.8)$ & $-0.77 \quad(-0.92,-0.62)^{* * *}$ & $0.91 \quad(<0.0001)$ \\
\hline Women & $21.6 \quad(3.3)$ & $22.2 \quad(3.7)$ & $-0.62(-0.72,-0.51) * * *$ & $0.95 \quad(<0.0001)$ \\
\hline
\end{tabular}

$*^{* * *} \mathrm{p}<0.0001$ ( $\mathrm{p}$-values from paired $\mathrm{t}$-tests) 
Table 2: Discrepancies in self-reported weights and heights and end-digit rounding preference by measured BMI category separately for men and women

\begin{tabular}{|c|c|c|c|c|c|c|c|c|c|c|}
\hline \multirow[b]{2}{*}{$\begin{array}{l}\text { Measured } \\
\text { BMI Cate- } \\
\text { gory }^{\mathrm{a}}\end{array}$} & \multirow{2}{*}{\multicolumn{2}{|c|}{ N (\%) }} & \multicolumn{4}{|c|}{ Weight } & \multicolumn{4}{|c|}{ Height } \\
\hline & & & \multicolumn{2}{|c|}{$\begin{array}{l}\text { Discrepancy }\left(\mathrm{SR}^{\mathrm{b}}-\right. \\
\quad \text { Measured) } \\
\mathrm{Kg}, \text { mean }(95 \% \mathrm{Cl})\end{array}$} & \multicolumn{2}{|c|}{$\begin{array}{c}\text { Percent reporting end- } \\
\text { digit } 0 \text { or } 5 \\
\%(95 \% \mathrm{CI})\end{array}$} & \multicolumn{2}{|c|}{$\begin{array}{c}\text { Discrepancy (SRb } \\
\text { Measured) } \\
\mathrm{cm}, \text { mean }(95 \% \mathrm{CI})\end{array}$} & \multicolumn{2}{|c|}{$\begin{array}{c}\text { Percent reporting end } \\
\text { digit } 0 \text { or } 5 \\
\%(95 \% \mathrm{Cl})\end{array}$} \\
\hline \multicolumn{11}{|l|}{ Men } \\
\hline $\begin{array}{l}\text { Underweight } \\
(<18.5)\end{array}$ & 5 & $(I)$ & 1.13 & $(0.40,1.86)^{*}$ & $0 \%$ & $(0 \%, 52 \%)$ & -1.40 & $(-5.78,2.98)$ & $0 \%$ & $(0 \%, 52 \%)$ \\
\hline $\begin{array}{l}\text { Normal } \\
(18.5-<23)\end{array}$ & 133 & (37) & -0.08 & $(-0.46,0.29)$ & $29 \%$ & $(21 \%, 37 \%)^{*}$ & 1.18 & $\begin{array}{l}(0.80 \\
1.56)^{* * * *}\end{array}$ & $32 \%$ & $\begin{array}{l}(24 \%, \\
41 \%)^{* * * *}\end{array}$ \\
\hline $\begin{array}{l}\text { Overweight } \\
(23-<25)\end{array}$ & 88 & $(25)$ & -1.34 & $\begin{array}{l}(-2.18,- \\
0.50)^{* *}\end{array}$ & $36 \%$ & $\begin{array}{l}(26 \%, \\
47 \%)^{* * *}\end{array}$ & 1.69 & $\begin{array}{l}(1.20 \\
2.17)^{* * * *}\end{array}$ & $36 \%$ & $\begin{array}{l}(26 \%, \\
47 \%)^{* * * *}\end{array}$ \\
\hline Obese $(25+)$ & 132 & $(37)$ & -1.58 & $\begin{array}{l}(-2.27,- \\
0.89)^{* * * *}\end{array}$ & $36 \%$ & $\begin{array}{l}(28 \% \\
45 \%)^{* * * *}\end{array}$ & 1.92 & $\begin{array}{l}(1.57 \\
2.27)^{* * * *}\end{array}$ & $43 \%$ & $\begin{array}{l}(35 \% \\
52 \%)^{* * * *}\end{array}$ \\
\hline \multicolumn{11}{|l|}{ Women } \\
\hline $\begin{array}{l}\text { Underweight } \\
(<18.5)\end{array}$ & 36 & (9) & 1.18 & $(0.30,2.06)^{* *}$ & $19 \%$ & $(8 \%, 36 \%)$ & 1.65 & $\begin{array}{l}(0.79 \\
2.5 \mathrm{I})^{* * * *}\end{array}$ & $44 \%$ & $\begin{array}{l}(28 \%, \\
62 \%)^{* * *}\end{array}$ \\
\hline $\begin{array}{l}\text { Normal } \\
(18.5-<23)\end{array}$ & 229 & $(60)$ & -0.38 & $\begin{array}{l}(-0.59,- \\
0.18)^{* * * *}\end{array}$ & $23 \%$ & $(17 \%, 29 \%)$ & 1.13 & $\begin{array}{l}(0.93 \\
1.34)^{* * * *}\end{array}$ & $29 \%$ & $\begin{array}{l}(23 \% \\
35 \%)^{* * *}\end{array}$ \\
\hline $\begin{array}{l}\text { Overweight } \\
(23-<25)\end{array}$ & 54 & $(14)$ & -0.94 & $\begin{array}{l}(-1.45,- \\
0.42)^{* * *}\end{array}$ & $33 \%$ & $(21 \%, 47 \%)^{*}$ & 1.36 & $\begin{array}{l}(0.86 \\
1.87)^{* * * *}\end{array}$ & $39 \%$ & $\begin{array}{l}(26 \%, \\
53 \%)^{* * * *}\end{array}$ \\
\hline Obese $(25+)$ & 64 & $(17)$ & -2.21 & $\begin{array}{l}(-2.89,- \\
1.53)^{* * * *}\end{array}$ & $33 \%$ & $(22 \%, 46 \%)^{*}$ & 1.83 & $\begin{array}{l}(1.30 \\
2.35)^{* * * *}\end{array}$ & $41 \%$ & $\begin{array}{l}(29 \% \\
54 \%)^{* * * *}\end{array}$ \\
\hline
\end{tabular}

a Using Thai classification (15)

$\mathrm{b} S \mathrm{R}=$ self-reported

${ }^{*} \mathrm{p}<0.05 ; *_{\mathrm{p}}<0.01$; *** $\mathrm{p}<0.00$ I (for discrepancies, $\mathrm{p}$-values were from paired t-tests; for end-digit tests, $\mathrm{p}$-values were from exact binomial tests of proportion $=0.20$ )

normal weight women reporting weight, all other subgroups showed end-digit preference that was significantly different from $20 \%$ (Table 2). End-digit preference appeared to be a little more pronounced with increasing weight status.

\section{Diagnostic test values}

Table 3 shows the test values when self-reported weight and height were used as tools to determine weight status (obesity and overweight/obese). Defining obesity as BMI $>25 \mathrm{~kg} / \mathrm{m}^{2}$, specificity was very high for both men and women $(97.2 \%$ and $100 \%$, respectively), as were positive predictive values $(94.2 \%$ and $100 \%)$. Sensitivity was considerably lower, $74.2 \%$ and $71.9 \%$, respectively, for men and women. Negative predictive values were $86.6 \%$ and $94.7 \%$ for men and women, respectively.

When self-reports were used to determine overweight/ obese in both sexes, sensitivity was higher and specificity lower than when used to determine obesity. Specificity was $94 \%$ and $99 \%$, and sensitivity was $78 \%$ and $77 \%$ for men and women, respectively. PPVs were similar in men, but decreased slightly in women. NPVs decreased by much larger amounts -- 12 percentage points in men and four in women.

\section{Prevalence estimates}

Obesity prevalences based on self-reported data for men and women were $29.1 \%$ and $12.0 \%$, respectively. These prevalences, underestimated by $7.8 \%$ in men and $4.7 \%$ in women, were statistically significantly lower than the "true" prevalences based on measured values of $36.9 \%$ and $16.7 \%$ (Table 3 ).

When ROC techniques as recommended by Dauphinot were applied, the proportions correctly classified as obese were maximized at BMI thresholds of $24.5 \mathrm{~kg} / \mathrm{m}^{2}$ for men and $24.4 \mathrm{~kg} / \mathrm{m}^{2}$ for women. Using these reduced thresholds, obesity prevalences increased to $33.8 \%$ for men and $15.9 \%$ for women, which were not statistically significantly different from the "true" prevalences (Table 3 ). Stated another way, application of the "reduced BMI threshold" method significantly reduced under-estimation of obesity prevalence estimates to $3.1 \%$ in men and $1.1 \%$ in women.

For overweight/obese, the reduced BMI thresholds were $22.4 \mathrm{~kg} / \mathrm{m}^{2}$ for men and $22.5 \mathrm{~kg} / \mathrm{m}^{2}$ for women (Table 3 ). These thresholds increased the prevalence estimates for men from $50.3 \%$ to $58.9 \%$, which was not statistically significantly different from the "true" prevalence of $61.5 \%$. 
Table 3: Test values for diagnosis of obesity and overweight/obesity based on self-reported data comparing standard Thai BMI thresholds and reduced BMI thresholds, and effects on prevalence estimates

\begin{tabular}{|c|c|c|c|c|c|c|c|}
\hline & Sensitivity & Specificity & $\begin{array}{c}\text { Positive } \\
\text { predictive value } \\
\text { (PPV) }\end{array}$ & $\begin{array}{c}\text { Negative } \\
\text { predictive value } \\
\text { (NPV) }\end{array}$ & $\begin{array}{c}\text { Measured } \\
\text { prevalence }\end{array}$ & $\begin{array}{l}\text { Self-reported } \\
\text { prevalence }\end{array}$ & $\begin{array}{c}\text { TCS }^{\text {a }} \text { self- } \\
\text { reported preva- } \\
\text { lence }\end{array}$ \\
\hline \multicolumn{8}{|l|}{ Obesity } \\
\hline \multicolumn{8}{|l|}{ Men } \\
\hline $\begin{array}{l}\text { Thai BMI } \\
\text { threshold }(\geq 25)\end{array}$ & 74.2 & 97.3 & 94.2 & 86.6 & 36.9 & 29.1 & 22.7 \\
\hline $\begin{array}{l}\text { Reduced BMI } \\
\text { threshold }(\geq 24.5)\end{array}$ & 81.1 & 93.8 & 88.4 & 89.5 & - & 33.8 & 28.0 \\
\hline \multicolumn{8}{|l|}{ Women } \\
\hline $\begin{array}{l}\text { Thai BMI } \\
\text { threshold }(\geq 25)\end{array}$ & 71.9 & 100.0 & 100.0 & 94.7 & 16.7 & 12.0 & 10.0 \\
\hline $\begin{array}{l}\text { Reduced BMI } \\
\text { threshold }(\geq 24.4)\end{array}$ & 85.9 & 98.1 & 90.1 & 81.4 & - & 15.9 & 12.2 \\
\hline \multicolumn{8}{|l|}{ Overweight/Obese } \\
\hline \multicolumn{8}{|l|}{ Men } \\
\hline $\begin{array}{l}\text { Thai BMI } \\
\text { threshold }(\geq 23)\end{array}$ & 77.7 & 93.5 & 95.0 & 72.5 & 61.5 & 50.3 & 44.4 \\
\hline $\begin{array}{l}\text { Reduced BMI } \\
\text { threshold }(\geq 22.4)\end{array}$ & 87.7 & 86.2 & 91.0 & 81.4 & - & 58.9 & 51.8 \\
\hline \multicolumn{8}{|l|}{ Women } \\
\hline $\begin{array}{l}\text { Thai BMI } \\
\text { threshold }(\geq 23)\end{array}$ & 77.1 & 99.2 & 97.8 & 90.7 & 30.8 & 24.3 & 19.6 \\
\hline $\begin{array}{l}\text { Reduced BMI } \\
\text { threshold }(\geq 22.5)\end{array}$ & 87.3 & 97.0 & 92.8 & 94.5 & - & 29.0 & 23.2 \\
\hline
\end{tabular}

a Thai Cohort Study ( $n=38,815$ men, 47,070 women)

For women, the prevalence estimate increased from $24.3 \%$ to $29.0 \%$, also not significantly different from the "true" prevalence of $30.8 \%$.

By maximizing the proportion of individuals correctly classified, the Dauphinot method increases sensitivity, decreases specificity, and decreases the PPV [7]. In this sample, PPVs were decreased by between $4 \%$ and $10 \%$ (Table 3).

When the reduced BMI thresholds were applied to the entire TCS sample, obesity prevalence estimates increased by $5.3 \%$ (from $22.7 \%$ to $28.0 \%$ ) for men and by $2.2 \%$ (10.0\% to $12.2 \%$ ) for women (Table 3 ). Prevalence estimates of overweight/obese increased by $7.4 \%$ for men and $3.6 \%$ for women (Table 3 ).

\section{Discussion}

This study examined the validity of self-reported weights and heights for determining obesity and overweight/ obese in Thai men and women. Previous studies examining this issue have been on populations in developed countries and, except for two studies in Japan, none were conducted in Asian countries. Understanding the validity and accuracy of self-reported anthropometric data is important so that such data can be used with confidence, or at least with knowledge of its limitations, when economizing on resources is necessary for accomplishing the research. To the best of our knowledge, our study is the first to examine this topic in a developing nation in Asia. In many rapidly urbanizing countries such as Thailand, the emerging obesity epidemic is a growing public health problem requiring urgent large-scale community intervention [16]. Self-reported weights and heights in these settings would provide a practical and economical means of monitoring the effectiveness of intervention program trends.

Our study showed results consistent with findings in Western populations. Previous studies have reported very high correlations, more than 0.90 , between self-reported and measured weight, height, and BMI in men and women under 60 years of age $[2-4,17]$. In our study, correlations were high in both sexes, ranging from 0.91 to 0.95. In most studies, as well as in ours, correlations for height were marginally lower than for weight. This phenomenon could be a reflection of many individuals' greater awareness of their weight than of their height. 
Most studies found an under-reporting of weight and an over-reporting of height. Studies of general population samples in France [2], Scotland [18], the US [6,11], the UK [3], Brazil [17], Australia [19], Sweden [20], Canada [21], and Italy [22] reported weight discrepancies ranging from $-0.54 \mathrm{~kg}$ to $-0.76 \mathrm{~kg}$ for men and from $-0.85 \mathrm{~kg}$ to $2.5 \mathrm{~kg}$ for women. The men in our Thai sample showed weight and height discrepancies that were comparable to these. For the women, discrepancy in mean height was comparable, but the discrepancy of mean weight, at -0.62 $\mathrm{kg}$, was smaller.

Our results were more similar to those from Western countries than to Japan. The Japanese study showed extremely small weight and height discrepancies -- less than $0.05 \mathrm{~kg}$ for weight and less than $0.08 \mathrm{~cm}$ for height in both sexes. The high degree of accuracy was attributed partly to the practice of annual health checkups in Japan and to the sample being a homogenous group of middleclass public servants recruited from a single workplace.

Actual body weight status had been found to be a major determinant of weight under-reporting in many studies [2,4,18-21]. A similar pattern was seen in our study, where weight reporting discrepancy was not significant for normal weight individuals, but highly significant (about 2 $\mathrm{kg}$ ) for obese men and women.

The influence of weight status on height reporting was less consistent. The Japanese study [4] found no increase in discrepancy. The French [2], Australian [19], and Swedish [20] studies found moderate increases. The Canadian study [21] found significant trends only in men, while the Scottish study [18] showed a trend in the opposite direction. Our study showed moderate increases in height reporting discrepancies in both sexes. The finding in our study of significant height over-reporting among individuals of normal weight status was not observed in other studies. This may be because short stature is socially undesirable in Thai culture, resulting in a tendency to over-estimate height. But another explanation is that Thai identity cards show head-and-shoulder photos against a wall scale, and heights are recorded at the top of the hair line. In our stadiometer measurements, height was read against the top of the skull, ignoring hair thickness. This could account for most of the difference between adult Thai selfreports of height and actual measurements using the criteria we adopted.

The proportions of people with end-digit preference increased slightly with weight status, suggesting that the greater reporting discrepancy among overweight and obese individuals may be due to a greater tendency to round weight down and round height up.
Specificity for detecting obesity in our study, as in other studies $[4,17,19-21]$, was very high, typically between $97 \%$ and $100 \%$. This indicated that few individuals reported weight and height that would put them in the obese category unless they really were obese. Sensitivity was more variable, with values ranging from $59 \%$ to $89 \%$ $[4,17,19-21]$. Sensitivity values in our study $(74.2 \%$ and $71.9 \%$ for men and women, respectively) were lower than in the Japanese [4] and Scottish [18] studies, higher than in the Canadian [21] study, and comparable to the Swedish [20], Australian [19], US [10], and Brazilian [17] studies.

Compared to obesity determination, when self-reported weights and heights were used to determine overweight/ obese, specificity was generally lower and sensitivity higher. This suggests that, as a tool for determining weight status, self-reported weights and heights give more accurate assessment of obesity than of overweight/obese.

Previous research has been consistent in finding PPVs and NPVs for obesity that were higher in women than in men. This was also the case in our study, where PPV and NPV for obesity were $100 \%$ and $95 \%$, respectively, in women, and $94 \%$ and $87 \%$ in men. This suggests that the determination of weight status from self-reported weights and heights was more accurate in women than men, a point noted in a few previous studies [2,22,23].

Overall, obesity prevalence underestimation in our study was similar to many studies (e.g., Canada [21], Sweden [20], and Australia [19]), but higher than in others (e.g., Switzerland [7] and Japan [4]). Application of the "reduced BMI threshold" method significantly reduced under-estimation of obesity prevalence estimates and decreased PPVs in our study. The decrease in PPVs implies that reduced thresholds should not be used for individual weight status classification for clinical or diagnostic purposes, which supports Dauphinot's [7] observation that "... the revised obesity threshold should be applied only on population data."

Several limitations and observations should be noted.

Although our study suggests self-reported weights and heights can be used successfully to determine weight status, we caution against extrapolating this finding to Thailand as a whole because our participants were sampled from STOU, which requires completion of high school education for enrollment. In contrast, less than half of the Thai general population has completed high school [24]. Another difference is in the age distribution. Being an open university, STOU admits students of any age, but the majority is under 40 years of age ( $87 \%$ of TCS members are under 40 years old). The use of volunteers, who may 
be more willing to honestly report their weights and heights than the general population, may also influence the findings in this study. Further, the bias in self-reports obtained on campus, as in the present study, may differ from self-reports obtained in the home setting, where respondents may have access to weight and height instruments.

Prevalences of obesity were higher in the ancillary study than in the TCS $(29 \%$ versus $23 \%$ for men; $12 \%$ versus $10 \%$ for women). This could be due to the lower average age of the TCS sample compared to the ancillary sample, by 2.5 years for men and 5.1 years for women.

An exceptionally high proportion $(21 \%)$ of women in the TCS sample were underweight (BMI $<18.5 \mathrm{~kg} / \mathrm{m}^{2}$ ) based on self-reported data [25]. The underweight women in the ancillary study tended to over-report their weight, a finding consistent with the behavior of underweight women in other studies (e.g., Danubio [22]). This suggests that the prevalence of underweight women in TCS may be even higher than the one-fifth of the female population indicated from self-reported data. But due to the small numbers (only 36 women in the ancillary study (9\%) were underweight), further data are needed to examine the validity of self-reported data among underweight women.

In summary, educated young Thais under-report weight and over-report height in ways similar to their counterparts in developed countries. These reporting biases can be overcome with a simple adjustment of BMI thresholds to provide obesity prevalence estimates within statistical error of the true prevalence. Our findings suggest that selfreporting of weights and heights can provide economical and valid measures of weight status in high school-educated populations in developing countries, but further work is needed to confirm these findings in other settings.

\section{Competing interests}

The authors declare that they have no competing interests.

\section{Authors' contributions}

LL, SS, and AS jointly conceived the study. LL performed the analyses and drafted the manuscript. SS managed and coordinated the data collection. AS participated in the study conduct and manuscript preparation. All authors read and approved the final manuscript.

\section{Acknowledgements}

This study was supported by the International Collaborative Grants Scheme with joint grants from the Wellcome Trust UK (GR0587MA) and the Australian NHMRC (268055).

\section{References}

I. WHO: Obesity: preventing and managing the global epidemic. Geneva: World Health Organisation; 2000.

2. Niedhammer I, Bugel I, Bonenfant S, Goldberg M, Leclerc A: Validity of self-reported weight and height in the French GAZEL cohort. Int J Obes Relat Metab Disord 2000, 24: I I I I-I I I8.

3. Spencer EA, Appleby PN, Davey GK, Key TJ: Validity of selfreported height and weight in 4808 EPIC-Oxford participants. Public Health Nutr 2002, 5:56I-565.

4. Wada K, Tamakoshi K, Tsunekawa T, Otsuka R, Zhang H, Murata C, Nagasawa N, Matsushita K, Sugiura K, Yatsuya H, Toyoshima H: Validity of self-reported height and weight in a Japanese workplace population. Int J Obes (Lond) 2005, 29:1093-1099.

5. Gorber SC, Tremblay M, Moher D, Gorber B: A comparison of direct vs. self-report measures for assessing height, weight and body mass index: a systematic review. Obes Rev 2007, 8:307-326.

6. McAdams MA, Van Dam RM, Hu FB: Comparison of self-reported and measured BMI as correlates of disease markers in US adults. Obesity (Silver Spring) 2007, I 5:188-196.

7. Dauphinot V, Wolff H, Naudin F, Gueguen R, Sermet C, Gaspoz JM, Kossovsky MP: New obesity body mass index threshold for self-reported data. J Epidemiol Community Health 2009, 63: I 28-I 32.

8. Nakamura K, Hoshino Y, Kodama K, Yamamoto M: Reliability of self-reported body height and weight of adult Japanese women. J Biosoc Sci 1999, 3 I :555-558.

9. Bostrom G, Diderichsen F: Socioeconomic differentials in misclassification of height, weight and body mass index based on questionnaire data. Int J Epidemiol 1997, 26:860-866.

10. Gillum RF, Sempos CT: Ethnic variation in validity of classification of overweight and obesity using self-reported weight and height in American women and men: the Third National Health and Nutrition Examination Survey. Nutr J 2005, 4:27.

II. Kuczmarski MF, Kuczmarski RJ, Najjar M: Effects of age on validity of self-reported height, weight, and body mass index: findings from the Third National Health and Nutrition Examination Survey, 1988-1994. J Am Diet Assoc 2001, I 0 I:28-34. quiz 3526

12. Paeratakul S, White MA, Williamson DA, Ryan DH, Bray GA: Sex, race/ethnicity, socioeconomic status, and $B M I$ in relation to self-perception of overweight. Obes Res 2002, 10:345-350.

13. Wardle J, Haase AM, Steptoe A: Body image and weight control in young adults: international comparisons in university students from 22 countries. Int J Obes (Lond) 2006, 30:644-65I.

14. Sleigh AC, Seubsman SA, Bain C: Cohort profile: The Thai Cohort of 87, I34 Open University students. Int J Epidemiol 2008, 37:266-272.

15. WHO (Western Pacific Region): The Asia-Pacific perspective: redefining obesity and its treatment. In International Associates for the study of obesity Edited by: taskforce lo. Melbourne: Health Communications Australia; 2000.

16. Misra $A$, Khurana L: Obesity and the metabolic syndrome in developing countries. J Clin Endocrinol Metab 2008, 93:S9-30.

17. Fonseca MJ, Faerstein E, Chor D, Lopes CS: [Validity of selfreported weight and height and the body mass index within the "Pro-saude" study]. Rev Saude Publica 2004, 38:392-398.

18. Bolton-Smith C, Woodward M, Tunstall-Pedoe H, Morrison C: Accuracy of the estimated prevalence of obesity from self reported height and weight in an adult Scottish population. J Epidemiol Community Health 2000, 54:|43-I48.

19. Taylor AW, Dal Grande E, Gill TK, Chittleborough CR, Wilson DH, Adams RJ, Grant JF, Phillips P, Appleton S, Ruffin RE: How valid are self-reported height and weight? A comparison between CATI self-report and clinic measurements using a large cohort study. Aust N Z J Public Health 2006, 30:238-246.

20. Nyholm M, Gullberg B, Merlo J, Lundqvist-Persson C, Rastam L, Lindblad $U$ : The validity of obesity based on self-reported weight and height: Implications for population studies. Obesity (Silver Spring) 2007, I 5:197-208.

21. Shields M, Gorber SC, Tremblay MS: Estimates of obesity based on self-report versus direct measures. Health Rep 2008, 19:61-76.

22. Danubio ME, Miranda G, Vinciguerra MG, Vecchi E, Rufo F: Comparison of self-reported and measured height and weight: implications for obesity research among young adults. Econ Hum Biol 2008, 6:181-190. 
23. Flood V, Webb K, Lazarus R, Pang G: Use of self-report to monitor overweight and obesity in populations: some issues for consideration. Aust N ZJ Public Health 2000, 24:96-99.

24. Wittayakorn C: 2004-2005 Thai youth education status report: the root cause and guidelines for solutions. Bangkok: Ministry of Education; 2006.

25. Banwell C, Lim L, Seubsman SA, Bain C, Dixon J, Sleigh A: Body mass index and health-related behaviours in a national cohort of 87,I34 Thai open university students. I Epidemiol Community Health 2009, 63:366-372.

Publish with Bio Med Central and every scientist can read your work free of charge

"BioMed Central will be the most significant development for disseminating the results of biomedical research in our lifetime. "

Sir Paul Nurse, Cancer Research UK

Your research papers will be:

- available free of charge to the entire biomedical community

- peer reviewed and published immediately upon acceptance

- cited in PubMed and archived on PubMed Central

- yours - you keep the copyright

Submit your manuscript here:

http://www.biomedcentral.com/info/publishing_adv.asp 